\title{
Metallic versus biodegradable suture anchors for rotator cuff repair: a case control study
}

\author{
Umile Giuseppe Longo ${ }^{1,2^{*}}$ (D), Stefano Petrillo ${ }^{1,2}$, Mattia Loppini ${ }^{3,4}$, Vincenzo Candela ${ }^{1,2}$, Giacomo Rizzello ${ }^{1,2}$, \\ Nicola Maffulli, ${ }^{5,6}$ and Vincenzo Denaro ${ }^{1,2}$
}

\begin{abstract}
Backgrounds: Repair of full-thickness rotator cuff (RC) tears is routinely performed using suture anchors, which produce secure and effective soft tissue fixation to bone. The aim of this prospective study is to compare the longterm outcomes of single row arthroscopic rotator cuff repair (RCR) performed using metal or biodegradable suture anchors. The null hypothesis is that there is no difference in shoulder function using metal or biodegradable suture anchors as evaluated by UCLA shoulder score, Wolfgang criteria, and Oxford shoulder score.

Methods: Arthroscopic RCR was performed in 110 patients included in this case control study. They were divided into 2 groups of 51 and 59 patients respectively. Metal suture anchors were used in group 1, and biodegradable suture anchors in group 2. Results were obtained at a mean follow up of $4.05+2$ years. Clinical outcomes and functional outcomes were evaluated.

Results: The mean modified UCLA shoulder score was $26.9 \pm 7.1$ in group 1 , and $27.7 \pm 6.5$ in group $2(P=0.5)$; the mean Wolfgang score was $13.3 \pm 3.3$ in group 1 , and $14 \pm 2.6$ in group $2(P=0.3)$; the mean OSS was $23.7 \pm 11.4$ in group 1 , and $20.7 \pm 9.2$ points in group $2(P=0.1)$. The mean active anterior elevation was $163.5^{\circ}+28.2^{\circ}$ in group 1 and $163.6^{\circ} \pm 26.9$ in group $2(P=0.9)$; the mean active external rotation was $46^{\circ} \pm 19.7^{\circ}$ in group $\overline{1}$ and $44.6^{\circ} \pm 16.3^{\circ}$ in group $2(P=0.7)$. The mean strength in anterior elevation was $4.8 .02 \pm 23.52 \mathrm{~N}$ in group 1 , and $43.12+17.64 \mathrm{~N}$ in group $2(P=0.2)$; the mean strength in external rotation was $48.02+22.54 \mathrm{~N}$ in group 1 and $46.06 \pm 17.64 \mathrm{~N}$ in group $2(P=0.6)$; the mean strength in internal rotation was $67.62 \pm 29.4 \mathrm{~N}$ in group 1 , and $68.6 \pm 25.48 \mathrm{~N}$ in group $2(P=0.9)$.

Conclusions: There are no statistically significant differences at a mean follow-up of $4.05 \pm 2$ years in clinical and functional outcomes of single row arthroscopic RCR using metallic or biodegradable suture anchors for $\mathrm{RC}<5 \mathrm{~cm}$.
\end{abstract}

Keywords: Suture anchors, Rotator cuff, Arthroscopy, Metal, Biodegradable

\section{Background}

Repair of full-thickness rotator cuff (RC) tears is routinely performed using suture anchors, which produce secure and effective soft tissue to bone repair [1-3]. Outcome of RC surgery is unpredictable, because the biological process that leads the tendon to reattach to the bone have not been clearly identified [4-10]. Metal

\footnotetext{
* Correspondence: g.longo@unicampus.it

'Department of Orthopaedic and Trauma Surgery, Campus Bio-Medico University, Via Alvaro del Portillo, 200, 00128 Trigoria, Rome, Italy

${ }^{2}$ Centro Integrato di Ricerca (CIR) Campus Bio-Medico University, Via Alvaro del Portillo, 21, 00128 Rome, Italy

Full list of author information is available at the end of the article
}

suture anchors ensure a safe and long-term fixation while biodegradable suture anchors provide fixation for a short period, during which the tissue heal [11].

Metal suture anchors provide a good long term fixation but are often associated with well documented complications such as migration, chondral damage, imprisonment of the anchor within the joint, major technical difficulty with revision surgery and problems with magnetic resonance (MRI) imaging [12-14].

The use of biodegradable implants in arthroscopic rotator cuff repair (RCR) procedures is relatively recent. In fact, biodegradable anchors avoid the potential risk of

(c) The Author(s). 2019 Open Access This article is distributed under the terms of the Creative Commons Attribution 4.0 International License (http://creativecommons.org/licenses/by/4.0/), which permits unrestricted use, distribution, and reproduction in any medium, provided you give appropriate credit to the original author(s) and the source, provide a link to the Creative Commons license, and indicate if changes were made. The Creative Commons Public Domain Dedication waiver (http://creativecommons.org/publicdomain/zero/1.0/) applies to the data made available in this article, unless otherwise stated. 
metal anchors of bone resorption and implant dislodgement $[15,16]$. Other advantages of biodegradable over metal implants include less postoperative MRI artifacts and easier revision surgery $[17,18]$. Nevertheless, three main disadvantages are associated with the use of biodegradable suture anchors: higher costs, undesired biological response [19] and shorter fixation time. Moreover, biomechanical studies demonstrated that metal anchors present a better fixation strength when compared with biodegradable anchors [20]. Several clinical studies reported excellent results with the use of biodegradable implants, fully superimposable to those obtained with non-absorbable devices [11, 21-23]. However, only one short term follow up randomized control trial [24] compared the clinical and functional outcome of arthroscopic RCR performed with metal or biodegradable suture anchors. The aim of the study is to compare the long-term clinical outcomes of arthroscopic RCR performed with metal or biodegradable suture anchors.

The null hypothesis is that there is no difference in shoulder function using metal or biodegradable suture anchors as evaluated by UCLA shoulder score, Wolfgang criteria, and Oxford shoulder score.

\section{Methods}

Our institutional ethics review board approved the study.

\section{Type of study}

Case control study

\section{Eligibility criteria}

Patients were included in the study if they underwent arthroscopic RCR and the following conditions were present at the time of surgery: RC tear, absence of shoulder instability, absence of shoulder's fractures, MRI evidence of full-thickness RC tear, duration of symptoms of at least 3 months, inadequate response to non-operative management (including non-steroidal anti-inflammatory drugs, physiotherapy, rest, and one local corticosteroid injection), a repairable RC tear found at the time of surgery. Patients with pathology of the tendon of the long head of the biceps were also included in the study.

Exclusion criteria were: inflammatory joint disease, prior surgery on the affected shoulder, labral pathology, degenerative arthritis of the glenohumeral joint, symptomatic arthritis of the acromioclavicular joint, $\mathrm{RC}$ arthropathy, inability to complete questionnaires.

In 51 patients, RCR was performed using metallic suture anchors (Corkscrew, Arthrex, Naples, FL) (Group 1), while in 59 patients RCR was performed using biodegradable suture anchors (Biocorkscrew, Arthrex, Naples, FL) (Group $2)$. Of the 110 patients enrolled in the present investigation, results at an average of $4.05+2$ year were available for 108 patients. Two patients, both in group 1, were excluded from the study because of cognitive disorders. All tears were $<5 \mathrm{~cm}$ in size in both group.

\section{Evaluation}

The mean follow up period were $4.05 \pm 2$ year (range 1 to 10 years) from the surgery. Age; sex; arm dominance; history of trauma; location of RC tear; dimension of the RC tear; biceps tendon rupture or tendinopathy; type of treatment of biceps tendon; acromioplasty; number of anchors used; post-operative range of motion (ROM); postoperative modified University of California, Los Angeles (UCLA) [25] shoulder rating scale; post-operative Wolfgang criteria shoulder score; post-operative Oxford shoulder score (OSS) [26, 27]; post-operative strength of anterior elevation, external and internal rotation were evaluated.

\section{Clinical assessment}

A modified UCLA [25] shoulder rating scale was used to evaluate strength (5 points), shoulder pain (10 points), function (10 points), active forward flexion (5 points) and patient satisfaction (5 points). The maximum score obtainable is 35 , and the results were classified as excellent (34-35 points), good (28-33), fair (21-27), or poor $(0-20)$.

The Wolfgang criteria were used to assess post-operative shoulder pain (4 points), active abduction (4 points), strength (4 points) and patient satisfaction (1 point or minus 1 point). The maximum score obtainable is 17 , and the results were classified as excellent (14-17 points), good (11-13 points), fair (8-10 points) or poor (0-7 points).

Postoperatively, all patients completed the Italian version of the (OSS) [26], a questionnaire that evaluates shoulder function, pain and strength in relationship with daily life activities. The minimum score is 12 points and the maximum score is 60 points. The higher is the score, the worse the condition of the shoulder.

\section{Range of motion and strength}

Clinical and functional evaluations were performed by two blinded examiners. Patients were positioned supine with the shoulder at $90^{\circ}$ of abduction in the scapular plane. Supine passive and active forward elevation (sagittal plane), internal and external rotation $\mathrm{ROM}\left(90^{\circ} \mathrm{ab}-\right.$ duction) were evaluated with a standard universal goniometer [28].

A dynamometer (mod.CH 15 K20-KERN Balingen Germany) was used to measure the strength of anterior elevation, internal and external rotation of the shoulder, and the results obtained were expressed in Newton $(\mathrm{N})$. Both examiners performed three measurements for each ROM and strength measurement investigated. The 
average value for each variable was used for statistical purposes.

\section{Sample size and demographic details}

Patients were divided into two groups: metallic suture anchors (Group 1), or biodegradable suture anchors (Group 2). Demographic and surgical details of the patients enrolled in the study are shown in Table 1.

\section{Arthroscopic technique}

Arthroscopic RCRs were performed by two orthopaedic surgeons, expert in the use of both metallic and biodegradable implants.

Patients underwent brachial plexus block (associated, in 21 patients, with general anaesthesia). RCRs were performed with patients in a lateral decubitus position and the affected arm at approximately $45^{\circ}$ of

Table 1 Demographic and surgical details

\begin{tabular}{|c|c|c|c|}
\hline VARIABLE & GROUP 1 & GROUP 2 & $\bar{P}$ \\
\hline AGE $($ mean + sd) & $56.5+10$ & $58.1+9$ & 0.5 \\
\hline SEX & & & 1 \\
\hline Male & 26 & 27 & \\
\hline Female & 23 & 32 & \\
\hline ARM DOMINANCE & & & 0.2 \\
\hline Yes & 40 & 42 & \\
\hline No & 9 & 17 & \\
\hline TRAUMA & & & 0.3 \\
\hline Yes & 12 & 10 & \\
\hline No & 37 & 49 & \\
\hline LOCATION & & & 1 \\
\hline Supraspinatus & 25 & 30 & \\
\hline Supraspinatus+ Infraspinatus & 24 & 29 & \\
\hline DIMENSION & & & 0.1 \\
\hline$<1 \mathrm{~cm}$ or $1-3 \mathrm{~cm}$ & 25 & 41 & \\
\hline $3-5 \mathrm{~cm}$ & 24 & 18 & \\
\hline LHB patology & & & 0.2 \\
\hline Tear & 18 & 24 & \\
\hline Tendinophaty & 10 & 14 & \\
\hline Absent & 21 & 11 & \\
\hline LHB Treatment & & & 0.3 \\
\hline No & 17 & 19 & \\
\hline Tenotomy & 19 & 25 & \\
\hline Tenodesis & 13 & 5 & \\
\hline \multicolumn{4}{|l|}{ ACROMIOPLASTY } \\
\hline Performed & 22 & 29 & \\
\hline Not performed & 27 & 30 & \\
\hline NUMBER OF ANCHORS (mean + sd) & $1.71+0.72$ & $1.76+0.67$ & 0.5 \\
\hline
\end{tabular}

Sd Standard Deviation, LHB Long head biceps abduction and $20^{\circ}$ of forward flexion. Distraction of the shoulder joint was accomplished with 4.5 to 6.5 $\mathrm{kg}$ of traction. A diagnostic arthroscopy was made. Bleeding was controlled using radiofrequency and adrenalin mixed to the irrigation fluid. A subacromial decompression was performed in the presence of a type III Acromion.

Footprint of the greater tuberosity was abraded. RCR was performed placing one row of suture anchors double loaded with $\mathrm{N}^{\circ} 2$ Fiberwire (Corkscrew, Arthrex, Naples, FL) (Group 1) or (Biocorkscrew, Arthrex, Naples, FL) (Group 2) just in the lateral aspect of the footprint. The number of suture anchors varied with the size of the tear. We used 2 or 3 suture anchors with a single row technique in patients with a tear larger than $3 \mathrm{~cm}$ and 1 suture anchor in patients with a tear $<$ of $3 \mathrm{~cm}$.

\section{Post-operative management}

The two groups had the same post-operative management. Patients used a sling for the affected arm with an abduction pillow for 6 weeks. Movements allowed were: active elbow flexion; active elbow extension; passive external rotation. Terminal extension and overhead stretching were restricted until 6 weeks post-operatively and manual work and overhead activities were restricted until 12 months. Strengthening and rehabilitation of the rotator cuff, deltoid and scapular muscles were initiated at 10 or 12 weeks after surgery.

\section{Statistics}

1 Statistical analyses were conducted considering the following outcome scores: total modified UCLA shoulder score, total Wolfgang criteria shoulder score and total OSS. We considered also active and passive ROM and strength of anterior elevation, internal rotation and external rotation. The independent variables analyzed were: age; sex; arm dominance; history of trauma; location and dimension of the rotator cuff tear; biceps tendon rupture or tendinopathy; type of treatment of biceps tendon; acromioplasty; number of anchors used. Comparison between the 2 groups for each independent variable was carried out with the Student $t$ test for continuous variables and the $\times 2$ test for categorical variables. The outcome variables considered (shoulder outcome scores, active and passive ROM, muscle strength) were compared using the Student $t$ test. A one-way ANCOVA was performed to compare the effectiveness of the type of suture anchors on outcome scores, ROM and strength whilst controlling for the length of followup. The effect size was evaluated according Cohen's guidelines: 0.2 - small effect, 0.5 - moderate effect, 0.8 large effect. Significance was set at $P<0.05$. 


\section{Sample size calculation}

In the present study, we enrolled a series of 110 consecutive patients who underwent $\mathrm{RC}$ repair at our institution without an a priory power analysis. However, we undertook a post hoc power analysis using UCLA score. According to previous study, the UCLA shoulder score minimal clinically important difference is 2.96 points in the 35-point scale [29]. We estimated that our study had $90 \%$ of power with an alfa error probability of 0.05 , an effect size of 0.65 and a minimum of 50 patients for each group.

\section{Results}

From 197 potentially eligible patients, 180 decided to be examined for eligibility and 110 met the eligible criteria to be enrolled in this study. The mean follow-up was $4.05 \pm 2$ years (range 1-10). As 2 patients from group 1 were excluded, the final evaluation includes 108 patients (53 men and 55 women; mean age $57.3 \pm 9.5$ years, range 29-76). No patient experienced infection, neurological or vascular complications after surgery. The comparison between groups did not show significant differences between them for each independent variable considered (Table 2).

According to the results of our study, at a mean followup of $4.05 \pm 2$ years, clinical and functional differences between arthroscopic RCR performed with metal or biodegradable suture anchors are not significant $(P<0.5)$.

Sixty-four subjects underwent $R C$ repair using 1 suture anchor. 44 subjects underwent $\mathrm{RC}$ repair using 2 or more suture anchors. Overall, the mean modified UCLA shoulder score was $24.7 \pm 4.9$ points in subjects who underwent RC repair using 1 suture anchor, and $25.5 \pm 4.3$ in who underwent $\mathrm{RC}$ repair using 2 or more suture anchors $(P<0.5)$; the mean Wolfgang criteria scores was $12.2 \pm 2.2$ points in group who underwent $\mathrm{RC}$ repair using 1 suture anchor, and $13 \pm 1.5$ in group who underwent $\mathrm{RC}$ repair using 2 or more suture anchors $(P<0.5)$; the mean Oxford shoulder scores were $20.4 \pm 8.1$ points in group who underwent $\mathrm{RC}$ repair using 1 suture anchor, and $17.4 \pm 5.9$ in group who underwent RC repair using 2 or more suture anchors $(P<0.5)$.

The mean passive anterior elevation was $166.1^{\circ} \pm 20.3$ in group who underwent $\mathrm{RC}$ repair using 1 suture

Table 2 Outcome scores

\begin{tabular}{llll}
\hline \multirow{2}{*}{$\begin{array}{l}\text { Outcome } \\
\text { scores }\end{array}$} & \multicolumn{2}{l}{ MEAN + STANDARD DEVIATION } & $P$ \\
\cline { 2 - 3 } & GROUP 1 & GROUP 2 & \\
\hline UCLA & $26.9+7.1$ & $27.7+6.5$ & 0.5 \\
WOLFGANG & $13.3+3.3$ & $14+2.6$ & 0.3 \\
OSS & $23.7+11.4$ & $20.7+9.2$ & 0.1 \\
\hline
\end{tabular}

OSS Oxford shoulder score anchor, and $179.6^{\circ} \pm 13.6$ in group who underwent $\mathrm{RC}$ repair using 2 or more suture anchors $(P<0.5)$; the mean passive external rotation was $71.7^{\circ} \pm 21^{\circ}$ in group who underwent RC repair using 1 suture anchor, and $72.2^{\circ} \pm 18^{\circ}$ in group who underwent $\mathrm{RC}$ repair using 2 or more suture anchors $(P<0.5)$; the mean passive internal rotation was $82.1^{\circ} \pm 12.9^{\circ}$ in group who underwent $\mathrm{RC}$ repair using 1 suture anchor, and $81.3^{\circ} \pm 13.7^{\circ}$ in group who underwent $\mathrm{RC}$ repair using 2 or more suture anchors $(P<0.5)$. The mean active anterior elevation was $162.4^{\circ} \pm 27.1^{\circ}$ in group who underwent $R C$ repair using 1 suture anchor, and $164.5^{\circ} \pm 25.8$ in group who underwent $\mathrm{RC}$ repair using 2 or more suture anchors $(P<0.5)$; the mean active external rotation was $44^{\circ} \pm 17.7^{\circ}$ in group who underwent $\mathrm{RC}$ repair using 1 suture anchor, and $42.6^{\circ} \pm 14.3^{\circ}$ in group who underwent RC repair using 2 or more suture anchors $(P<0.5)$.

The mean strength in anterior elevation was $44.02 \pm 19.52 \mathrm{~N}$ in group who underwent $\mathrm{RC}$ repair using 1 suture anchor, and $39.12 \pm 13.64 \mathrm{~N}$ in group who underwent RC repair using 2 or more suture anchors $(P<0.5)$; the mean strength in external rotation was $43.02+20.54$ $\mathrm{N}$ in group who underwent $\mathrm{RC}$ repair using 1 suture anchor and $41.06 \pm 15.64 \mathrm{~N}$ in group who underwent $\mathrm{RC}$ repair using 2 or more suture anchors $(P<0.5)$; the mean strength in internal rotation was $66.61 \pm 28.4 \mathrm{~N}$ in group who underwent $\mathrm{RC}$ repair using 1 suture anchor, and $67.5 \pm 24.48 \mathrm{~N}$ in group who underwent $\mathrm{RC}$ repair using 2 or more suture anchors $(P<0.5)$.

No statistical differences were found in terms of functional outcome using 1 or 2 or more suture anchors $(P<0.5)$;

\section{Group 1 (metallic suture anchors)}

49 subjects underwent $\mathrm{RC}$ repair with metallic suture anchors. The average of postoperative modified UCLA shoulder score was $26.9+7.1$ points (range 6-35). According to the modified UCLA shoulder rating system, in 7 patients (14\%) the results were considered excellent, in 22 patients $(46 \%)$ good, in 10 patients $(20 \%)$ fair, and in the remaining 10 patients $(20 \%)$ poor.

The average of postoperative Wolfgang criteria shoulder score was $13.3 \pm 3.3$ points (range $2-17$ ). According to Wolfgang criteria shoulder score, in 29 patients (59\%) the results were considered excellent, in 11 patients (22\%) were good, in $6(12 \%)$ patients were fair, and in the remaining 3 patients $(6 \%)$ poor.

The average of postoperative OSS was $23.7 \pm 11.4$ points (range: $12-51$ ).

The mean postoperative passive and active forward flexion, external and internal rotation ROM is reported in Table 3. Table 3 also lists the mean strength value in anterior elevation, external and in internal rotation ROM. 
Table 3 Group 1 functional results

\begin{tabular}{|c|c|c|c|c|c|c|c|c|}
\hline \multirow{2}{*}{$\begin{array}{l}\text { Group } 1 \\
\text { Metallic }\end{array}$} & \multicolumn{3}{|c|}{ PASSIVE ROM } & \multicolumn{2}{|c|}{ ACTIVE ROM } & \multicolumn{3}{|c|}{ STRENGHT (N) } \\
\hline & $\overline{\text { A.E. }}$ & E.R. & I.R. & $\overline{\text { A.E. }}$ & E.R. & $\overline{\text { A.E. }}$ & E.R. & I.R. \\
\hline MEAN & 169.4 & 73.9 & 84.3 & 163.5 & 46 & 48.02 & 48.02 & 67.62 \\
\hline T.D & 23.6 & 23 & 15.1 & 28.2 & 19.7 & 23.52 & 22.54 & 29.4 \\
\hline MAX & 180 & 90 & 90 & 180 & 90 & 107.8 & 107.8 & 107.8 \\
\hline MIN & 90 & 10 & 30 & 90 & 0 & 19.6 & 14.7 & 9.8 \\
\hline
\end{tabular}

$R O M$ range of motion, $A E$ anterior elevation, $E R$ external rotation, $I R$ internal rotation

Four of the patients in this group were involved in recreational volleyball, and 3 in recreational soccer: all returned to their pre-injury levels of sports.

\section{Group 2 (biodegradable suture anchors)}

The average postoperative modified UCLA shoulder score was $27.7 \pm 6.5$ points (range 6-35). 1. According to the modified UCLA shoulder rating scale, 12 patients (20\%) were excellent, 22 patients (37\%) were good, 17 (29\%) were fair, and the remaining 8 patients (14\%) were poor.

The average of postoperative Wolfgang criteria shoulder score was $14 \pm 2.6$ points (range 4-17). According to the Wolfgang criteria shoulder score, 35 patients (60\%) were considered excellent, 20 patients $(34 \%)$ good, 2 (3\%) fair, and the remaining 2 patients (3\%) poor.

The average of postoperative OSS was $20.7 \pm 9.2$ points (range: 12-46).

The mean postoperative passive and active forward flexion, external and internal rotation ROM is reported in Table 4. Table 4 also lists the mean strength value in anterior elevation, external and in internal rotation ROM.

Two of the patients in this group were involved in recreational tennis, and both returned to their pre-injury levels of sports.

\section{Group 1 vs group 2}

The comparison between the two groups did not show any statistically significant differences for any of the outcome variable considered.

Table 4 Group 2 functional results

\begin{tabular}{|c|c|c|c|c|c|c|c|c|}
\hline \multirow{2}{*}{$\begin{array}{l}\text { Group } 2 \\
\text { Biodegradable }\end{array}$} & \multicolumn{3}{|c|}{ PASSIVE ROM } & \multicolumn{2}{|c|}{ ACTIVE ROM } & \multicolumn{3}{|c|}{ STRENGHT (N) } \\
\hline & A.E. & E.R. & I.R. & A.E. & E.R. & A.E. & E.R. & I.R. \\
\hline MEAN & 173.1 & 74.4 & 83.5 & 163.6 & 44.6 & 43.12 & 46.06 & 68.6 \\
\hline ST.D & 19.9 & 20 & 15.9 & 26.9 & 16.3 & 21.56 & 17.64 & 25.48 \\
\hline$\Delta \mathrm{X}$ & 180 & an & 90 & 180 & م० & 107.8 & 102.9 & 10 \\
\hline MIN & 100 & 20 & 30 & 90 & 15 & 9.8 & 16.66 & 3 \\
\hline
\end{tabular}

$R O M$ range of motion, $A E$ anterior elevation, $E R$ external rotation, $I R$ internal rotation
Overall, the mean modified UCLA shoulder score was $26.9 \pm 7.1$ points in group 1 , and $27.7 \pm 6.5$ in group 2 $(P=0.5)$; the mean Wolfgang criteria scores was $13.3 \pm 3.3$ points in group 1 , and $14 \pm 2.6$ in group 2 $(P=0.3)$; the mean Oxford shoulder scores were $23.7 \pm 11.4$ points in group 1 , and $20.7 \pm 9.2$ in group 2 $(P=0.1)$.

The mean passive anterior elevation was $169.4^{\circ} \pm 23.6$ in group 1 , and $173.1^{\circ} \pm 16.9$ in group $2(P=0.3)$; the mean passive external rotation was $73.9^{\circ} \pm 23^{\circ}$ in group 1 , and $74.4^{\circ} \pm 20^{\circ}$ in group $2(P=0.9)$; the mean passive internal rotation was $84.3^{\circ} \pm 15.1^{\circ}$ in group 1 , and $83.5^{\circ} \pm 15.9^{\circ}$ in group $2(P=0.8)$. The mean active anterior elevation was $163.5^{\circ} \pm 28.2^{\circ}$ in group 1 , and $163.6^{\circ} \pm 26.9$ in group $2(P=0.9)$; the mean active external rotation was $46^{\circ} \pm 19.7^{\circ}$ in group 1 , and $44.6^{\circ} \pm 16.3^{\circ}$ in group $2(P=0.7)$.

The mean strength in anterior elevation was $48.02+23.52 \mathrm{~N}$ in group 1 , and $43.12+17.64 \mathrm{~N}$ in group $2(P=0.2)$; the mean strength in external rotation was $48.02+22.54 \mathrm{~N}$ in group 1 and $46.06 \pm 17.64 \mathrm{~N}$ in group $2(P=0.6)$; the mean strength in internal rotation was $67.62 \pm 29.4 \mathrm{~N}$ in group 1 , and $68.6 \pm 25.48 \mathrm{~N}$ in group $2(P=0.9)$.

\section{Discussion}

This study compared the long-term clinical and functional outcomes of patients who underwent arthroscopic RCR using metal or biodegradable suture anchors.

The findings of our study are similar to those reported in a randomized controlled trial [24] comparing the outcomes at a short-term follow up of RCR performed using biodegradable or metallic suture anchors.

The first types of suture anchors used for RCR were metallic. However, they may be associated with well documented complications such as migration, incarceration of the metal implant within the joint, chondral damage, loosening and technical difficulty with revision surgery [12-14]. Mobilization of metal implants can be identified at radiography [30]. Moreover, metal implants can produce artefacts in MRI studies.

Biodegradable suture anchors have been used since the 1990s. Biodegradable devices provide the necessary initial strength, and their mechanical characteristics during degradation decline slowly. This allow appropriate healing [31]. Moreover, the pullout strength of biodegradable suture anchors is comparable to that of metal anchors [32].

However, biodegradable suture anchors present disadvantages when compared with metallic implants, including higher costs, limited fixation time and severe major complications. One complication described is foreignbody reaction, which ranges from mild fluid accumulation to sterile discharging sinuses to irreversible tissue 
damage. In these cases, histopathology has consistently shown sterile, nonspecific inflammatory response [19]. Anchor dislodgement was reported in 13 of 30 patients with pain after RCR with biodegradable anchors [30], while in other studies disintegration of the implant was reported [16], and also humeral head osteolysis [15]. However, complications associated with biodegradable suture anchors are relatively uncommon, and with only few cases out of hundreds of thousands of implanted anchors.

From a clinical point of view, there is a lack of information about the differences between metallic and biodegradable suture anchors in RCR. Arthroscopic repair is well established for the management of RC tears, and many different techniques of repair have been described. Nevertheless, only few studies focused on the comparison between different implant materials. This information can be useful for the surgeons such as the institutions.

Although the range of follow-up is quite large, no significant statistical difference between long and short term patients was found. In our analysis, we considered three different shoulder scores (UCLA, Wolfgang and OSS), such as active and passive ROM and muscles strength. The UCLA shoulder score, Wolfgang criteria and OSS were higher in group 2 while active ROM was better in group 1 . Moreover, the strength of anterior elevation and external rotation was better in group 1 while the strength of internal rotation was better in group 2 . However, none of these differences were statistically significant.

Major strengths of the present study are that two fully trained surgeons performed all the operations using a well-established technique and the same type of metal or biodegradable suture anchors. In addition, the follow up evaluations were performed by two independent blinded assessors following standard measurements guidelines [33]. Our follow up, at an average of 4.05 years, is long enough to consider that, by then, the results of surgery had stabilised, the repaired tissue healed and the function and muscle strength were recovered.

Limitations of the study are that we did not perform post-operative imaging evaluation in our patients, and that we have very large range of follow-up. However, our previous study in this field showed that, although there is a definite rate of post-repair rotator cuff failure, this is often asymptomatic, and therefore post-operative imaging in and by itself should not be considered a measure of failure [34-37]. We are mounting further studies in which we plan to include imaging as an outcome measure. Bioabsorbable anchors may produce inflammatory reactions, with a reactive synovitis associated with pain and stiffness that does not respond to the use of anti-inflammatory drugs [38]. It would be interesting to know, in future studies, whether these imaging features are correlated with clinical outcome.

Rotator cuff surgery aims to provide tendon fixation secure enough to hold the repaired tendon in place until biological healing occurs [34-37]. Several factors may be implicated in failure of rotator cuff repairs, including suture or knot failure, inadequate tendon to bone fixation, and lack of tendon to bone healing. However, biodegradable implants present important disadvantages.

Based on the results of the present investigation, we routinely use metallic suture anchors in patients undergoing arthroscopic RCR, to reduce costs of the operations and risk of severe complications. In our hands, biodegradable and metallic suture anchors provide similar clinical and functional outcomes for RCR. Obviously, we have to specify that our results refer to a single type of biodegradable or metal suture anchor. A biomechanical study [39] demonstrated that subtle design differences can affect the mechanical behavior of biodegradable suture anchors, and therefore our results cannot be translated to all implants available.

Additional biomechanical studies and appropriately powered randomized controlled trials with long term follow up are needed to better understand the real advantage of biodegradable over metal implants in arthroscopic RCR procedures.

According to the ANCOVA analysis, there was a significant difference in mean values of active and passive $\mathrm{ROM}$ and strength of anterior elevation, internal rotation and external rotation (Table 5). On the other hand, there was no significant difference in mean values of UCLA, Wolfgang and OSS scores (Table 5).

\section{Conclusion}

There are no statistically significant differences at a mean follow-up of $4.05 \pm 2$ years in clinical and

Table 5 ANCOVA analysis for active and passive ROM and strength of anterior elevation, internal rotation and external rotation between the group 1 and 2

\begin{tabular}{llll}
\hline Dependent variable & $F$ (Test Statistic) & $P$ value & Partial Eta Squared \\
\hline OSS & 1985 & 0.162 & 0.131 \\
UCLA & 0.365 & 0.547 & 0.003 \\
WS & 1166 & 0.283 & 0.011 \\
Passive ROM AE & 6225 & 0.014 & 0.056 \\
Passive ROM ER & $1,422,404$ & $<0.0001$ & 0.931 \\
Passive ROM IR & $1,889,092$ & $<0.0001$ & 0.947 \\
Active ROM AE & 13,645 & $<0.0001$ & 0.115 \\
Active ROM ER & $2,798,922$ & $<0.0001$ & 0.964 \\
Strength AE & $310,575,137$ & $<0.0001$ & 1.0 \\
Strength ER & $388,582,105$ & $<0.0001$ & 1.0 \\
Strength IR & $214,173,738$ & $<0.0001$ & 1.0 \\
\hline
\end{tabular}


functional outcomes of single row arthroscopic RCR using metallic or biodegradable suture anchors for $\mathrm{RC}<$ $5 \mathrm{~cm}$. Moreover, passive and active ROM of the shoulder and $\mathrm{RC}$ muscles strength show no statistically significant differences between metal or biodegradable suture anchors. The type of implant material used (metal vs. biodegradable) did not influence the outcome of arthroscopic rotator cuff repair.

\section{Abbreviation}

MRI: Magnetic resonance imaging; OSS: Oxford shoulder score; RC: Rotator cuff; RCR: Rotator cuff repair; RCR: Rotator cuff repair; ROM: Range of motion; UCLA: University of California, Los Angeles

\section{Acknowledgements}

Not applicable

\section{Authors' contributions}

All authors have read and approved the manuscript, UGL: manuscript preparation, study design, database interpretation and manuscript revision, SP: manuscript preparation, database interpretation and statistical analysis, GR: manuscript preparation, figures and tables preparation, study design, NM: Manuscript preparation and database interpretation, VD: Study design, manuscript revision. All authors have read and approved the manuscript.

\section{Funding}

No funding was obtained for this study.

\section{Availability of data and materials}

The dataset supporting the conclusions of this article will be provided upon reasonable request from the corresponding authors.

\section{Ethics approval and consent to participate}

The ethics committee of the university "Campus Bio Medico" of Rome approved the study and all patients gave written consent to participate.

\section{Consent for publication}

Written informed consent to publish this information was obtained from study participants. All the data are available for the consultation.

\section{Competing interests}

UGL and GR are members of the Editorial Board of BMC Musculoskeletal Disorders. The remaining authors declare that they have no conflict of interest.

\section{Author details \\ 'Department of Orthopaedic and Trauma Surgery, Campus Bio-Medico University, Via Alvaro del Portillo, 200, 00128 Trigoria, Rome, Italy. ${ }^{2}$ Centro Integrato di Ricerca (CIR) Campus Bio-Medico University, Via Alvaro del Portillo, 21, 00128 Rome, Italy. ${ }^{3}$ Department of Biomedical Sciences, Humanitas University, Via Rita Levi Montalcini 4, 20090 Pieve Emanuele, Milan, Italy. ${ }^{4}$ Department of Orthopaedic and Trauma Surgery, Humanitas Clinical and Research Center, Via Alessandro Manzoni 56, 20089 Rozzano, Milan, Italy. ${ }^{5}$ Department of Musculoskeletal Disorders, Faculty of Medicine and Surgery, University of Salerno, Salerno, Italy. ${ }^{6}$ Centre for Sports and Exercise Medicine, Barts and The London School of Medicine and Dentistry, Mile End Hospital, 275 Bancroft Road, London E1 4DG, England.}

Received: 27 May 2018 Accepted: 13 September 2019 Published online: 25 October 2019

\section{References}

1. Longo UG, Salvatore G, Rizzello G, Berton A, Ciuffreda M, Candela V, Denaro $V$. The burden of rotator cuff surgery in Italy: a nationwide registry study Arch Orthop Trauma Surg. 2017:137:217-24.

2. Longo UG, Berton A, Papapietro N, Maffulli N, Denaro V. Epidemiology, genetics and biological factors of rotator cuff tears. Med Sport Sci. 2012:57:1-9.
3. Audigé L, Flury M, Müller AM, Durchholz H, Panel ACC. Complications associated with arthroscopic rotator cuff tear repair: definition of a core event set by Delphi consensus process. J Shoulder Elb Surg. 2016;25: 1907-17.

4. Longo UG, Franceschi F, Ruzzini L, Spiezia F, Maffulli N, Denaro V. Higher fasting plasma glucose levels within the normoglycaemic range and rotator cuff tears. Br J Sports Med. 2009;43:284-7.

5. Longo UG, Franceschi F, Spiezia F, Marinozzi A, Maffulli N, Denaro V. The low-profile Roman bridge technique for knotless double-row repair of the rotator cuff. Arch Orthop Trauma Surg. 2011;131:357-61.

6. Franceschi F, Longo UG, Ruzzini L, Rizzello G, Maffulli N, Denaro V. Soft tissue tenodesis of the long head of the biceps tendon associated to the Roman bridge repair. BMC Musculoskelet Disord. 2008:9:78.

7. Franceschi F, Longo UG, Ruzzini L, Rizzello G, Maffulli N, Denaro V. The Roman bridge: a "double pulley - suture bridges" technique for rotator cuff repair. BMC Musculoskelet Disord. 2007;8:123.

8. Longo UG, Lamberti A, Rizzello G, Maffulli N, Denaro V. Synthetic augmentation in massive rotator cuff tears. Med Sport Sci. 2012;57:168-77.

9. Longo UG, Berton A, Khan WS, Maffulli N, Denaro V. Histopathology of rotator cuff tears. Sports Med Arthrosc. 2011;19:227-36.

10. Del Buono A, Oliva F, Longo UG, Rodeo SA, Orchard J, Denaro V, Maffulli N Metalloproteases and rotator cuff disease. J Shoulder Elb Surg. 2012;21:200-8.

11. Tan CK, Guisasola I, Machani B, Kemp G, Sinopidis C, Brownson P, Frostick S. Arthroscopic stabilization of the shoulder: a prospective randomized study of absorbable versus nonabsorbable suture anchors. Arthroscopy. 2006;22: $716-20$

12. Jeong JH, Shin SJ. Arthroscopic removal of proud metallic suture anchors after Bankart repair. Arch Orthop Trauma Surg. 2009;129:1109-15.

13. Silver MD, Daigneault JP. Symptomatic interarticular migration of glenoid suture anchors. Arthroscopy. 2000;16:102-5.

14. Kaar TK, Schenck RC, Wirth MA, Rockwood CA. Complications of metallic suture anchors in shoulder surgery: a report of 8 cases. Arthroscopy. 2001; 17:31-7.

15. Glueck D, Wilson TC, Johnson DL. Extensive osteolysis after rotator cuff repair with a bioabsorbable suture anchor: a case report. Am J Sports Med. 2005:33:742-4.

16. Kelly JD. Disintegration of an absorbable rotator cuff anchor six weeks after implantation. Arthroscopy. 2005:21:495-7.

17. McBirnie JM, Miniaci A, Miniaci SL. Arthroscopic repair of full-thickness rotator cuff tears using bioabsorbable tacks. Arthroscopy. 2005;21:1421-7.

18. Cummins CA, Strickland S, Appleyard RC, Szomor ZL, Marshall J, Murrell GA. Rotator cuff repair with bioabsorbable screws: an in vivo and ex vivo investigation. Arthroscopy. 2003;19:239-48.

19. Ambrose CG, Clanton TO. Bioabsorbable implants: review of clinical experience in orthopedic surgery. Ann Biomed Eng. 2004;32:171-7.

20. Barber FA, Herbert MA, Coons DA, Boothby MH. Sutures and suture anchors--update 2006. Arthroscopy. 2006;22:1063.e1061-9.

21. Magnusson L, Ejerhed L, Rostgård-Christensen L, Sernert N, Eriksson R, Karlsson J, Kartus JT. A prospective, randomized, clinical and radiographic study after arthroscopic Bankart reconstruction using 2 different types of absorbable tacks. Arthroscopy. 2006;22:143-51.

22. Ejerhed L, Kartus J, Funck E, Köhler K, Sernert N, Karlsson J. A clinical and radiographic comparison of absorbable and non-absorbable suture anchors in open shoulder stabilisation. Knee Surg Sports Traumatol Arthrosc. 2000;8: 349-55.

23. Elmlund AO, Kartus J, Rostgård-Christensen L, Sernert N, Magnusson L, Ejerhed L. A 7-year prospective, randomized, clinical, and radiographic study after arthroscopic Bankart reconstruction using 2 different types of absorbable tack. Am J Sports Med. 2009:37:1930-7.

24. Milano G, Grasso A, Salvatore M, Saccomanno MF, Deriu L, Fabbriciani C. Arthroscopic rotator cuff repair with metal and biodegradable suture anchors: a prospective randomized study. Arthroscopy. 2010;26: S112-9.

25. Ellman $\mathrm{H}$, Hanker $\mathrm{G}$, Bayer M. Repair of the rotator cuff. End-result study of factors influencing reconstruction. J Bone Joint Surg Am. 1986;68:1136-44.

26. Murena L, Vulcano E, D'Angelo F, Monti M, Cherubino P. Italian crosscultural adaptation and validation of the Oxford shoulder score. J Shoulder Elb Surg. 2010:19:335-41.

27. Younis F, Sultan J, Dix S, Hughes PJ. The range of the Oxford shoulder score in the asymptomatic population: a marker for post-operative improvement. Ann R Coll Surg Engl. 2011;93:629-33. 
28. Longo UG, Saris D, Poolman RW, Berton A, Denaro V. Instruments to assess patients with rotator cuff pathology: a systematic review of measurement properties. Knee Surg Sports Traumatol Arthrosc. 2012;20:1961-70.

29. Haque A, Pal Singh H. Does structural integrity following rotator cuff repair affect functional outcomes and pain scores? A meta-analysis. Should Elb. 2018;10:163-9.

30. Magee T, Shapiro M, Hewell G, Williams D. Complications of rotator cuff surgery in which bioabsorbable anchors are used. AJR Am J Roentgenol. 2003;181:1227-31

31. Kilicoglu O, Demirhan M, Akman S, Atalar AC, Ozsoy S, Ince U. Failure strength of bioabsorbable interference screws: effects of in vivo degradation for 12 weeks. Knee Surg Sports Traumatol Arthrosc. 2003;11:228-34.

32. Pietschmann MF, Fröhlich V, Ficklscherer A, Gülecyüz MF, Wegener B, Jansson V, Müller PE. Suture anchor fixation strength in osteopenic versus non-osteopenic bone for rotator cuff repair. Arch Orthop Trauma Surg. 2009;129:373-9.

33. AmericanAccademyof OrthopaedicSurgeons: Joint motion: method of measuring and recording. 1965.

34. Maffulli N, Longo UG, Franceschi F, Rabitti C, Denaro V. Movin and Bonar scores assess the same characteristics of tendon histology. Clin Orthop Relat Res. 2008;466(7):1605-11.

35. Longo UG, Franceschi F, Ruzzini L, Rabitti C, Morini S, Maffulli N, Denaro V. Characteristics at Haematoxylin and eosin staining of ruptures of the long head of the biceps tendon. Br J Sports Med. 2009:43(8):603-7. Epub 2007 Dec 10

36. Longo UG, Franceschi F, Ruzzini L, Rabitti C, Morini S, Maffulli N, Denaro V. Histopathology of the supraspinatus tendon in rotator cuff tears. Am J Sports Med. 2008:36:533-8.

37. Longo UG, Franceschi F, Ruzzini L, Rabitti C, Morini S, Maffulli N, Forriol F, Denaro V. Light microscopic histology of supraspinatus tendon ruptures. Knee Surg Sports Traumatol Arthrosc. 2007;15:1390-4.

38. Bostman OM. Osteolytic changes accompanying degradation of absorbable fracture fixation implants. J Bone Joint Surg (Br). 1991;73:679-82.

39. Barber FA, Coons DA, Ruiz-Suarez M. Cyclic load testing of biodegradable suture anchors containing 2 high-strength sutures. Arthroscopy. 2007;23: $355-60$

\section{Publisher's Note}

Springer Nature remains neutral with regard to jurisdictional claims in published maps and institutional affiliations.

Ready to submit your research? Choose BMC and benefit from:

- fast, convenient online submission

- thorough peer review by experienced researchers in your field

- rapid publication on acceptance

- support for research data, including large and complex data types

- gold Open Access which fosters wider collaboration and increased citations

- maximum visibility for your research: over $100 \mathrm{M}$ website views per year

At BMC, research is always in progress.

Learn more biomedcentral.com/submissions 